\title{
Towards a Shariah Compliance Model for Healthcare Centres with reference to Spiritual Healers: Issues and Challenges
}

Ramizah Wan Muhammad

Department of Islamic Law, Ahmad Ibrahim Kulliyyah of Laws International Islamic University Malaysia (IIUM)

\begin{abstract}
Generally, a good healthcare centre comprises of qualified manpower, right policies and right procedures in providing primary care, secondary care and tertiary care for the patients as well as in public health. Other than manpower, healthcare centres must also look at social, religious and cultural factors affecting the recipients of the healthcare services given by the healthcare centres. In this paper, the author will look at some pertinent issues such as the need to have spiritual healers in any healthcare centre to help the patients in dealing with fatal illness. The spiritual healer is to help the patient and give him motivation so that he could have a positive mind throughout his journey in battling with his illness. Sometimes we have patients who refused to listen to the doctor's advice. Thus, the role of the spiritual healer would be important in assisting the healthcare centres and its management to convince him. Another issue is the privacy, respect and trust between patients and doctors as well as with the management of the healthcare centres. One of the duties of the healthcare centres' management and doctors is, to respect the patient's religion and his faith. These three issues are amongst the important issues which every healthcare centre must look upon. Definitely there are a lot of challenges in addressing the above mentioned issues such as the procedures, methods on how to execute these issues and most importantly the perception of the public. In Islam, health care is one of the five important elements in which the Prophet SAW has mentioned in one hadith to be taken care of. A study has shown that a nation-building efforts has no meaningwithout the best public health and healthcare delivery system to the people.
\end{abstract}

KEYWORD; Shariah, Healthcare, Spiritual healers.

\section{INTRODUCTION}

Having the access to medical treatment is one of the basic needs of each and every citizen. Islam, as the comprehensive religion also promotes its followers to give and seek medical treatments. In one hadith narrated by Usamah ibn Sharik, where the Prophet Muhammad ( has been reported to have said"Make use of medical treatment, for Allah has not made a disease without appointing $a$ remedy for it, with the exception of one disease, namely old age". ${ }^{1}$ Unquestionably, being healthy is an ultimate aim of everyone.

The World Health Organization ("WHO") in defining "health" states in its 1946 Constitution that, "health is a state of complete physical, mental and social well-being and not merely the absence of disease or infirmity". ${ }^{2}$ Thus, in order to maintain a healthy body, having access to medical treatment is of paramount importance. Further, the dimension of health and the results from health care must

Ramizah Wan Muhammad

Department of Islamic Law,

Ahmad Ibrahim Kulliyyah of Laws,

International Islamic University Malaysia (IIUM),

Kuantan Campus.

Email: ramizah@iium.edu.my contain not only an indication of adjustments in the regularity and severity of diseases but also an approximation of well-being. This can be evaluated by gauging the enhancement in the quality of life related to health care.

The quality of life as defined by WHO is, "the individuals' perception of their position in life in the context of the culture and value systems in which they live and in relation to their goals, expectations, standards and concerns". ${ }^{3}$ From this definition, we understand that it encompasses a broader ranging concept which includes but is not limited to one's mental state, physical condition, personal beliefs, and social interactions. Thus, in the attempt to protect one's health, spiritual needs should not be neglected and it forms an integral part in establishing a comprehensive state of healthy-being.

In the Muslim worldview, health is defined as complete physical, psychological, social and spiritual wellbeing. ${ }^{4}$ The same goes for spiritual health as it forms a vital element of the Muslim health belief model. Muslims are spiritually obliged to care for their health and maintain their body. The rules and guidance can be found in the Qur'anic text and also in the hadith of the Prophet Muhammad s.a.w. For example, in Surah AlMuddathir, verse 4-5, Allah said in promoting 
personal hygiene:

\section{"Magnify your Lord! And purify your garments and} shun all filth."

Furthermore, in Surah Al-A'raf verse 31, Allah mentioned about having balance in diet intake: "Eat and drink, yet not in excess, for the Lord loves
not those who commit excess."

In one hadith narrated from 'Aishah, the wife of the Prophet, she said that "if the Messenger of Allah ( (㗪 wanted to sleep while he was Junub (sexually impure), he would perform Wudu', and if he wanted to eat he would wash his hands". ${ }^{5}$ This clearly shows the practice by the Prophet in promoting personal hygiene and the fact that he would wash his hand prior to consuming foods.

\section{Spiritual Healing}

Spirituality and religiosity has always been the core value in shaping human beings. People have always regards religion as one of the very basic needs and closely related to developing inner peace and confidence to oneself.

The notion of spirituality from the nursing point of view has a broader meaning than religion and comprises metaphysical ideas about life, its importance and purpose. ${ }^{6}$ However, it was argued that it is essential to distinguish between spirituality and religiosity. ${ }^{7}$ According to Wright ${ }^{8}$, spirituality is a combination of our moral values, which govern the process of how we act in this world, while religion is pictured as a divine pathway which ultimately lead to the practices that are appropriate to the God. On the other hand, there is no distinction made between religion and spirituality. Both are considered as one value that lead Muslims to One God, i.e. Allah. In Islam, there is no spirituality without religious thoughts and practices, and the religion is a tool that brings the spiritual path to salvation. ${ }^{9}$

Looking back in history, we understand that many educational institutions and health centers were founded by religious orders or spiritual thinkers. ${ }^{10}$ However, there has been a growing separation between religion and medicine in the last few centuries as the emphasis of medicine shifted to a more scientific focus. ${ }^{10}$ Nevertheless, starting from the 1950s, epidemiological studies seemed to display a good influence of spirituality to the development of the patient health and this has certainly initiated a series of lines of research on this subject from among the scholars. Religion began to be seen as advantageous for clinical results, and thereafter, spirituality based complementary treatment approach has started to develop. ${ }^{11}$ Presently, there have been several studies proving the benefit of religiosity and spirituality to mental and physical health. ${ }^{12}$ Thus, the dimension of health services has so far developed to a more broad scope in which it includes the spiritual approach taken by healthcare centres across the globe in their efforts to heal patients.

As religious principles and beliefs are complexly linked to cultural customs and norms, they shape patients' thinking and their approach to health and illness, thus influencing their expectations of the doctor-patient relationship as well as adherence to doctors' recommendations, guide medical-decision making, and influence health outcomes.

Hence the question arises, who will be the Spiritual Healer? To answer this question, reference should be made to other countries approach. For instance, the presence of professional chaplaincy organizations within healthcare across the globe has further proved the importance of religion and spirituality in supporting patients and their families within the hospital. ${ }^{13}$ The existence of these chaplaincy and pastoral care programs are effectively developed within the Judeo-Christian healing traditions. Since then, the hospitals have begun to integrate and accommodate other religions in order to cope with the increase of diverse population. ${ }^{14}$

As Islam is a religion growing intensely in Malaysia, the expectation is of course towards the scholars or religious officer to assist the patients and provide them with spiritual healing. The presence of religious officer in a healthcare centre or hospital is vital to promote the spiritual awareness among the Muslim patients. One of the roles of the religious officer is to counsel the patients and advise them on being calm in facing illness. A study has shown that the occurrence of psychiatric disorders in patients with cancer purportedly ranges from $29 \%$ to $47 \%$. Further, the depression and mental stress suffered by patients with cancer purportedly disrupt their compliance to treatment hence it will affect the whole course of the disease. ${ }^{15}$ Recent studies also suggested that, cancer is an important cause of emotional, mental, and behavioral reactions among the patients. ${ }^{15}$

From the above studies, it shows that one of the problems faced by patients with cancer is depression. A study also disclosed that, the most frequent health problems reported by attendees of spiritual centre was depression which formed $(45.1 \%){ }^{9}$ This demonstrates that spirituality approach might be a good option to deal with depression and managing stress level among patients. Thus, it shows the importance of having a proper organization or department in each healthcare centre that consist of spiritual healers of who can be closely involved with patients. A spiritual healer or an Imam has the capability of comforting patients especially those who suffered depression because of the illnesses they are associated to.

Among the role of an Imam or spiritual healer in 
healthcare centres is to encourage healthy behaviors through the Holy Qur'an and sunnah of the Prophet s.a.w in sermons. The spiritual healer has the capability of organizing a weekly religious sermon or class to enable the patients to be more conscious of their religion thus mending their relationship with God. ${ }^{14}$ This is essential to develop personal tranquility and self-reflection among the patients. The Prophet Muhammad s.a.w used to advice his followers to be patient and to persevere when inflicted with sickness. As narrated by Ibn 'Abbas in one hadith, where the Prophet s.a.w entered upon a sick man to pay him a visit, and said to him, "Don't worry, Allah willing, (your sickness will be) an expiation for your sins"..$^{16}$ The Prophet s.a.w also used to tell his companions that "no calamity befalls a Muslim but that Allah expiates some of his sins because of it, even though it were the prick he receives from a thorn". ${ }^{17}$ When an Imam is able to convey these reminders to the patients, it will eventually pacify their feeling and bring calmness upon them.

Another role of a spiritual healer is to assist the sick persons performing religious rites around life events and sicknesses. ${ }^{14}$ It is incumbent upon all Muslims to pray the five-daily-prayers no matter what condition they are in. From the history of Islam, we understand that the Prophet and his companion were ordered to adhere to the obligatory prayers even while in the heat of war. As Allah mentioned in Surah An-Nisa' verse 102:

\section{"And when you are among them and lead them in prayer, let a group of them stand [in prayer] with you and let them carry their arms. And when they have prostrated, let them be [in position] behind you and have the other group come forward which has not [yet] prayed and let them pray with you, taking precaution and carrying their arms"}

This commandment to preserve prayer even when the Muslims were at war shows the greater importance of the prayer itself. The Prophet ( also has beautifully described how a sick person should pray when he is unable to pray normally. From Imran bin Husain who said:

"I asked the Prophet ( ) about prayer for a sick person. He said: "He should perform prayer standing, if he is not able then sitting, if he is not able then on his side." 18

The spiritual healer is in the right position to advise the patients on how they should perform prayers as he is a qualified person in religion. The doctors might not have the experience or training specifically on how to pray during sickness. Thus, the presence of a spiritual healer in a hospital will be a good mechanism to teach and explain the patients on this matter.

Apart from the above roles, the spiritual healer is also expected to educate the hospitals' management, staff and medical officers. Among the challenges that might be faced by a spiritual healer is to prove that spiritual healing is one of the possible methods which can be used to ease the journey of an ill-person. Some doctors may think that only scientifically proven medical treatments are allowed and effective to help the patients. Thus, it is the responsibility of the spiritual healer to explain and educate them and on top of that to show the effectiveness of this method on the patients.

The next person who will always work with a doctor is the nurses. Thus, as much as the nurses are important to the doctor, a spiritual healer should be seen as equally significant too. A spiritual healer should not be seen as burden to any medical procedure. For example, a patient may refuse to undergo a treatment as he thinks that only God will always cure his illness without the need of taking any medication. In addition, some patients also interpret illness as a way of "submission to God's Will". They perceive illness as God's plan predestined upon them, therefore accepting their illness without assuming any role or responsibility to find the cure is honorable. ${ }^{7}$ However this concept is wrong and misunderstood by many people. One cannot simply leave everything at the hand of God without making any efforts. As the Prophet has mentioned in one of his hadith, "make use of medical treatment, for Allah has not made a disease without appointing a remedy for it, with the exception of one disease, namely old age". ${ }^{19}$ Therefore, it is the duty of the Imam to remind them of this and to motivate them during their hard times. When the patients understand that disease and healing are both coming from God, the spiritual healer could aid them to cope with illness by helping them to maintain hope in the Divine and strive to search for cure.

Based on the above, it brings us to the next role of a spiritual healer. He is expected to help the congregants in making healthcare decisions. He plays an integral role in healthcare decision making for Muslims within hospital. For instance, the spiritual healer can involve himself and sit in on a family meeting with medical officers to help the family make the decision based on the rulings of religion. Simply getting medical advice is insufficient as the family or patients themselves want to know the ruling of their religion on certain medical procedure such as the use of impure substance in medication. Thus, the involvement of a spiritual healer is seen to be a good tool in closing the gap between doctors and patients together with their family. In addition, he has the ability to inform the medical officers or the healthcare staff on what can be done and what cannot be done according to the rulings of the religion. This exemplifies the significant role a spiritual healer can play as explainer and advisor to the parties in complex healthcare-decision making.

It goes without saying that every single religion that exists in this world only teaches its follower to do 
good and abstain from evil doing. The religion of Islam too, always commands its followers to obey the commandments of Allah and to abstain from committing sins. However, like every other religions' followers, there might be a fraction of Muslims who live their life not performing their religious practices in worshiping Allah as the purpose of their lives. Thus, when they are stricken with death of their loved one or afflicted with illness, it might inspire them to re-evaluate the purpose and meaning of their lives. Their experience of sicknesses therefore might encourage them to change their daily plans and to further incorporate religious practices into their daily routine, and this ultimately lead to other changes in their lives.

\section{Challenges}

It has always been a challenge when it comes to a modification to a certain norms or practices. Similarly in this context; to introduce spiritual healing approach in healthcare centres will always trigger skeptical thoughts. It is a fact that medical science and spiritual thought are two separate branches and it seems impossible to knot both ties together. However, in order to achieve a greater cause, unification is an important element. Quality of life studies agree that religious and spiritual beliefs play an important role in patients' recovery and in how they are coping with illness. ${ }^{20}$

The first challenge is to meet the uniformity or unification between medical approach and spiritual approach. Medical officers or particularly the doctors might find the idea of having a spiritual healer 'lurking' around the hospital is uncomfortable. Being trained with medical knowledge and skills might fashion the doctors into thinking that only medical approach can cure the patients, not to mention the advancement of medical technologies and equipment which will increase the percentage of patients who recover. Thus it will increase the gap between medical science approach and spiritual healing approach. However, emphasis should be given that the idea of spiritual healing is not to eliminate the traditional approach of seeking a doctor's consultation. Rather, it is intented to merge with the medical science approach. When a patient is seeking medical treatment, a spiritual healer might also assist him as to regain his confidence and motivation to fight against the disease. Nevertheless, this scenario has not happened in all hospitals or to all medical practitioners. There are many hospitals which have provided such posts in their management system. But there may be a few medical practitioners who did not welcome their existence. It could be that all physicians would like to spiritually engage with their patients. ${ }^{21}$ At the same time, one must look at the attitude of the patients whenever a treatment is given to them.

For instance, when a person is diagnosed with cancer, especially when the cancer level reach to a chronic stage, he will lose his hope in life and would eventually give up even before starting the treatment. A spiritual healer can help the patient to regain his strength to fight the disease and not to give up easily. An Imam can remind a Muslim patient to be patient with the test and to emphasize that sickness is a test by Allah and $\mathrm{He}$ is indeed a Curer. As Allah mentioned in the Quran:

\section{"And when I am ill, it is He who cures me" 22}

Thus, it is important for a spiritual healer to remind patients and bring them towards God-fearing state of mind. This will basically help the doctors to approach their patients and start the necessary medical therapy on them.

Moreover, lack of education on spiritual care among the nurses and healthcare professionals might be another challenge that needs to be given attention to. While it is good to have a trained spiritual healer or Imam in hospitals, the doctors and nurses also should be exposed to spiritual care. The medical professionals should also play an active role in fulfilling the spiritual needs of their patients. Studies show that spiritual dimension is one of the important factors towards holistic care of a patient. ${ }^{6}$ One of the problems faced by healthcare centres are impaired holistic care to the patients because the spiritual aspect is frequently disregarded by health care professionals. ${ }^{6}$ Among the reasons given are the feelings of incompetence due to lack of training on spiritual care, shortage of time, different background of religion, ethical concerns and reluctance to deliver spiritual care. ${ }^{6}$

The International Council of Nurses (ICN) Code of Ethics identifies the nurse's role of upholding "an environment in which the human rights, values, customs and spiritual beliefs of the individual, family and community are respected". ${ }^{23}$ This notion has further supports from Nursing Board Malaysia through its Code of Professional Conduct for Nurses where it states that "the nurse is expected to provide a good standard of nursing care in the following manner: - Conscientiously assesses the physical, psychosocial and spiritual needs of each patient". ${ }^{24}$ This shows the important role of nurses to provide spiritual care along with the traditional medical care.

As mentioned earlier, spiritual care is part of the art of nursing and professional care. Spiritual care is commonly defined as recognizing, respecting, and meeting patients' spiritual needs. ${ }^{25}$ It may also include aiding participation in religious rites, being interactive through listening and talking with patients and referring them to other experts including spiritual healers or chaplains. ${ }^{6}$ The involvement of doctors and nurses in providing medical and spiritual care will result in holistic care towards their patients and thereafter increase the patients' chance of getting cured. 
Apart from having spiritually trained medical professionals, there is also a need for better facilities and appropriate equipment that could assist patients to get spiritual care. For instance, healthcare centres should form a group of committees who are well-trained with spiritual care and religious education. By having 'in-house' spiritual healer, patients will have easy access to consult them and to get personal advice. Furthermore, the 'in-house' Imam or spiritual healer will be more focused in assisting patients. Essentially, this could be a stepping stone to offering holistic care; both medically and spiritually to patients. Other facilities like mini library filled with religious or spiritual books could also be a good medium in perfecting the spiritual care. Patients usually have plenty of time in hospitals and they could make use of their time by reflecting and learning through the religious books.

However, lack of financial support might be a challenge for medical centres to provide the abovementioned facilities. To hire a professional spiritual healer and provide the relevant facilities might be a burden on healthcare centres. Ultimately, the cost will be shifted to the patients through their medical bills. Perhaps the government could play a significant role to counter this problem. For example, the government could, via its religious authority, provide a trained spiritual healer who is well versed in religious and human issues to each and every government hospital. Thus, patients could choose the government hospitals instead of going to the private hospitals. Besides that, a reasonable takaful plan that can be offered to patients could be one of the solutions to curb this problem.

\section{REFERENCES}

1. Sunan Abi Dawud 3855. In-book reference: Book 29, Hadith 1.

2. 1946 Constitution of the World Health Organization (WHO) Preamble to the Constitution of the World Health Organization as adopted by the International Health Conference, New York, 19-22 June, 1946; signed on 22 July 1946 by the representatives of 61 States.

3. WHOQOL and Spirituality, Religiousness and Personal Beliefs (SRPB). World Health Organization World Health Organization. Department of Mental Health. 1998 Geneva.

4. Al-Khayat M. Health: An Islamic Perspective. Alexandria, Egypt: World Health Organization Regional Office for the Eastern Mediterranean Region. 1997.

5. Sunan an-Nasa'i Vol. 1, Book 1, Hadith 257.

6. Baldacchino, D. Spiritual Care Education of Health Care Professionals, Religions.

7. 2015; 6, 2: 594-613.

8. Nabolsi, $M$, \& Carson, A. Spirituality, Illness and Personal Responsibility: The Experience of Jordanian Muslim Men With Coronary Artery Disease, Scandinavian Journal of Caring Sciences. 2011; 4: 716.
9. Wright S. How to be Happy at Work. Nursing Times. 1999; 95: 35.

10. Rassool, GH. The Crescent and Islam: Healing, Nursing and The Spiritual Dimension. Some Considerations towards an Understanding of the Islamic Perspectives on Caring, Journal of Advanced Nursing. 2000;32: 6: 1476-1484.

11. Lucchetti, G, Lucchetti, A, \&Puchalski, C. Spirituality in Medical Education: Global Reality?,

12. Journal of Religion and Health. 2012; 1 :. 3.

13. Samano, E, Ribeiro, L, Campos, A, Lewin, F, Filho, E, Goldenstein, P, Costa, L, \& Del Giglio, A.Use of Complementary and Alternative Medicine by Brazilian Oncologists, European Journal Of Cancer Care. 2005; 14: 2: 143-148.

14. Lucchetti, A, Lucchetti, G, Leao, F, Peres, M, \&Vallada, H (2016), 'Mental and Physical Health and Spiritual Healing: An Evaluation of Complementary Religious Therapies Provided by SpiritistCenters in the City of Sao Paulo, Brazil', Culture, Medicine And Psychiatry. 2016; 3: 404.

15. Vande Creek, Larry, and Laurel Burton. A White Paper: Professional Chaplaincy: Its Role and Importance in Healthcare. Journal of Pastoral Care. 2001; 55.1: 81-98.

16. Padela, Al. The Role of Imams in American Muslim Health: Perspectives of Muslim Community Leaders in Southeast Michigan', Journal of Religion and Health. 2011;50, ii, 359-373.

17. İzci, F, ìlgün, A, Fındıklı, E, \&Özmen, V. Psychiatric Symptoms and Psychosocial Problems in Patients with Breast Cancer', Meme SagligiDergisi / Journal of Breast Health. 2016;12, 3: 94-101.

18. Sahih al-Bukhari 5662 Book 75, Hadith 2.

19. Sahih al-Bukhari 5640 Book 75, Hadith 1.

20. Jami` at-Tirmidhi 372 Book 2, Hadith 224.

21. Sunan Abi Dawud 3855. In-book reference: Book 29, Hadith 1.

22. O'Connell, K, \& Skevington, S. The Relevance of Spirituality, Religion and Personal Beliefs to Health-related Quality of Life: Themes from Focus Groups in Britain, British Journal of Health Psychology, 2005;10; 3: 379-398.

23. Clayton L. Thompson: Barriers Boundaries \& Blessings: Ethical Issues in Physicians; Spiritual Involvement with Patients. 2000; 21. No.2. pp. 1-13

24. Surah Ash-Shu'ara, verse 80.

25. The ICN Code of Ethics For Nurses. International Council of Nurses, Geneva (Switzerland); 2000.

26. Code of Professional Conduct for Nurses; Nursing Board Malaysia, First Edition, Malaysia; 1998.

27. Melhem, G, Zeilani, R, Zaqqout, O, Aljwad, A, Shawagfeh, M, \& Rahim, M. 'Nurses' Perceptions of Spirituality and Spiritual Care Giving: A Comparison Study Among All Health Care Sectors in Jordan', Indian Journal of Palliative Care. 2016;1. 